\title{
Growth, Dielectric, Impedance and THG properties of Di- Ammonium Hydrogen Phospho Tartrate (DAHPT) single crystals
}

\author{
*R. Gandhimathi ${ }^{1}$, C. Muthu Krishnan ${ }^{2}$, P. Selvarajan ${ }^{3}$ \\ ${ }^{l}$ Govindammal Aditanar College for Women, Tiruchendur- 628215, Tamil Nadu \\ ${ }^{2}$ Sri K.G.S Arts College, Srivaikuntam- 628619, Tamil Nadu \\ ${ }^{3}$ Aditanar College of Arts and Science, Tiruchendur- 628215, Tamil Nadu
}

\begin{abstract}
Di-Ammonium Hydrogen Phospho Tartrate (DAHPT) single crystals have been grown successfully by slow evaporation technique. The structure of the grown crystal was estimated by single crystal X-ray diffraction technique. Dielectric study was carried out in the frequency range $20 \mathrm{~Hz}-1 \mathrm{MHz}$ and at different temperatures between $30^{\circ} \mathrm{C}$ and $150^{\circ} \mathrm{C}$. The impedance analysis was studied using an impedance analyser to find the impedance, bulk resistance, and DC conductivity of the sample. The values of nonlinear refractive index, nonlinear absorption and third order nonlinear susceptibility have been studied using Z-scan technique.

Keywords: dielectric, impedance, slow evaporation, Z-scan, single crystal
\end{abstract}

\section{Introduction}

In recent years, the need of nonlinear optical materials is much more than other materials because of their applications in Optoelectronics and Photonics [1,2]. With rapid progress in crystal growth technology, crystals having attractive NLO properties are being discovered. Organic materials are attractive due to their nonlinearities, ultra fast response time and relative ease of device processing. Nonlinear optical crystal capable of generating second harmonic frequency plays an important role in the domain of optoelectronics and photonics. NLO crystals with high frequency conversion second harmonic efficiencies and transparent in the visible and ultraviolet ranges are required for numerous device applications. Most of the organic NLO crystals are constituted by weak Vander walls and hydrogen bonds with conjugated $\pi$ electrons [3].In these respect amino acids are interesting materials for NLO applications [4]. Organic crystals are having some special properties of large optical nonlinearity and low cutoff wavelength in UV-region; therefore the organic NLO crystals are used in optical devices. However, the organic crystals have certain limitations such as poor mechanical and thermal stability. To overcome these problems, the combination of organic and inorganic hybrid compounds leads to find a new class of materials called semi organic materials having large optical nonlinearity, higher mechanical strength and chemical stability. A survey of literature shows some complexes of L-tartaric acid with inorganic salts such as zinc tartrate, strontium tartrate, manganese sulpho tartrate were reported [5-7]. In this paper, we report the growth of Diammonium hydrogen phospho tartrate (DAHPT) by SEST. The title compound was characterized by various techniques.

\section{Growth of DAHPT crystal}

Commercially available AR grades L-tartaric acid and Diammonium hydrogen chloride were taken in the ratio 1:1 to synthesize DAHPT. The calculated amounts of reactants were thoroughly dissolved into double distilled water. To avoid fungus few drops of hydrogen peroxide was added to the solution and it was constantly stirred for about 2 hours using a magnetic stirrer and was filtered using Whatmann filter paper. After filtration, the beakers containing the saturated solutions were covered with perforated sheets for controlled evaporation. Transparent, colorless crystals were obtained after a period of about 60 days (Fig. 1).

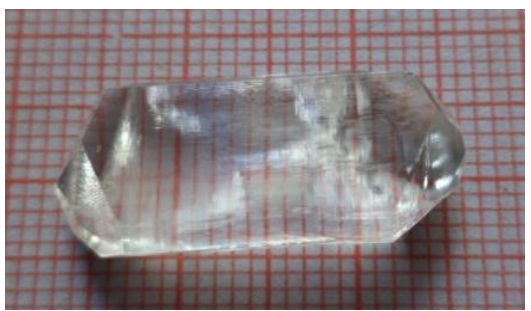

Fig.1: Photograph of DAHPT crystal 


\subsection{XRD studies}

\section{Results and Discussion}

The grown crystal of DAHPT was characterized by both powder and single crystal XRD studies. The single crystal XRD data was collected using a Brukes-Nonius MACH3/CAD4 X-ray diffractometer with $\mathrm{MoK}_{\alpha}$ radiation $(\lambda=0.71069 \AA \AA)$.

It is observed that the values of lattice constants obtained by powder XRD and single crystal XRD methods are to be almost the same and the data are given in the Table 1. The data indicates that the DAHPT crystal crystallizes in orthorhombic structure with space group $\mathrm{P} 2{ }_{1} 2_{1} 2_{1}$.

Table 1 Single crystal data of DAHPT crystal

\begin{tabular}{|c|c|c|c|c|c|c|l|}
\hline $\mathrm{a}(\AA)$ & $\mathrm{b}(\AA)$ & $\mathrm{c}(\AA)$ & $\alpha$ & $\beta$ & $\gamma$ & System & Space group \\
\hline $7.631(9)$ & $7.831(4)$ & $11.048(8)$ & $90^{\circ}$ & $90^{\circ}$ & $90^{\circ}$ & Orthorhombic & $\mathrm{P} 2{ }_{1} 2_{1} 2_{1}$ \\
\hline
\end{tabular}

\subsection{Dielectric analysis}

Dielectric studies furnish a great deal of information regarding the dielectric constant that arises from the contribution of different polarizations namely electronic, ionic, orientational and space charge are developed in the material subjected to the electric field variations. All these four polarizations are active at low frequencies. The dielectric characteristics of the material are important to know the transport phenomena and the lattice dynamics in the crystal. It also gives the information about the nature of atoms, ions, bonding and their polarization mechanism in the material. The dielectric study on DAHPT single crystal was carried out. The variation of dielectric constant with frequencies for various temperatures is shown in Fig. 2. It can be seen that the dielectric constant increases with increasing temperature after $1 \mathrm{KHz}$ and it is almost saturated when the frequency is increased to $1 \mathrm{MHz}$. This may be due to the fact that at lower frequencies all the polarizations are active whereas in the case of high frequency, i.e., above $1 \mathrm{MHz}$ only electronic and ionic polarizations are active. Those polarizations are independent of temperature [8-10]. The variation of dielectric loss with frequency for various temperatures is shown in Fig. 3. The curves suggest that dielectric loss is also strongly dependent on the frequency of the applied field. The high values of dielectric behaviour at low frequencies originate from space charge polarization mechanism. The characteristic of low dielectric loss at high frequencies classifies that the enhanced optical quality nature of the grown sample with lesser defects and it is desirable property for NLO applications.

A capacitor when charged under AC voltage will have some loss of current due to ohomic resistance or impedance by heat absorption. The $\mathrm{AC}$ conductivity $\left(\sigma_{\mathrm{ac}}\right)$ is calculated using the relation $\sigma_{\mathrm{ac}}=2 \pi f \varepsilon_{\mathrm{o}} \varepsilon_{\mathrm{r}} \tan \delta$, where $f$ is the frequency of the AC supply, $\varepsilon_{o}$ is the permittivity of free space or vacuum $\left(8.852 \times 10^{-12} \mathrm{~F} / \mathrm{m}\right), \epsilon_{\mathrm{r}}$ is the relative permittivity of dielectric constant and $\tan \delta$ is the dissipation factor or dielectric loss. The variation of AC conductivity with 1000/T for DAHPT crystal is depicted in the Fig. 4. [11-15]. The Arrhenius plot of $\ln \sigma \mathrm{T}$ versus 1000/T is shown in Fig. 5. It is evident from the graph that the conductivity increases with temperature. The value of activation energy for ionic migration was estimated from the graph. The line of best fit for the plot of $\ln \sigma \mathrm{T}$ versus $1 / \mathrm{T}$ obeys Arrhenius relationship $\sigma_{\mathrm{T}}=\sigma_{0} \exp \left(-\mathrm{E}_{\mathrm{a}} / \mathrm{kT}\right)$ where $\sigma_{\mathrm{o}}$ is the preexponent factor, $\mathrm{E}_{\mathrm{a}}$ the activation energy for the conduction process and $\mathrm{k}$ the Boltzmann's constant. Therefore, the sample exhibits Arrhenius type conductivity behavior in the temperature range of investigation. The activation energy of DAHPT, for the conduction process, calculated from the plot for DAHPT is found to be $0.0691 \mathrm{eV}$.

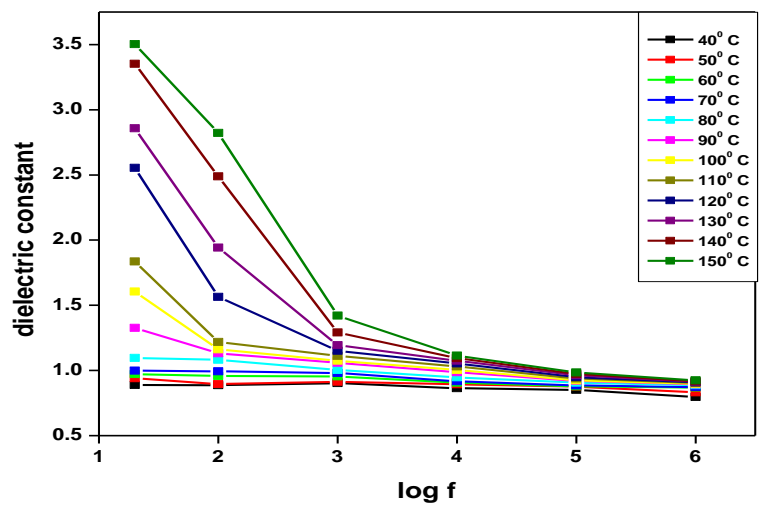

Fig. 2: Variation of dielectric constant of DAHPT crystal with frequency at different temperatures

National Conference on Current Advancements in Physics $3^{\text {rd }} \& 4^{\text {th }}$ February 2017 


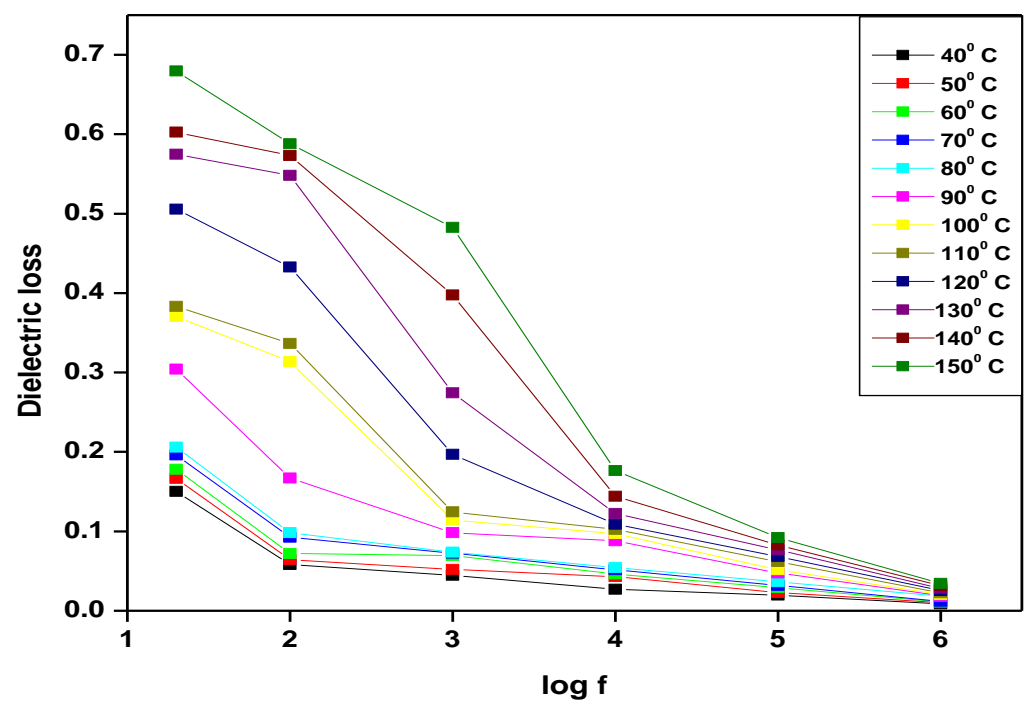

Fig. 3: Variation of dielectric loss of DAHPT crystal with frequency at different temperatures

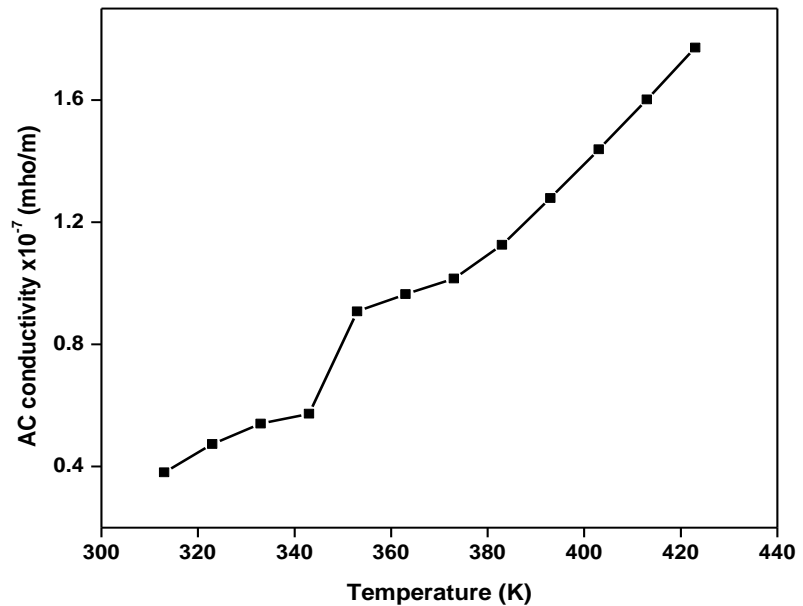

Fig. 4: Plot of AC conductivity versus 1000/T for DAHPT crystal at $1 \mathrm{kHz}$

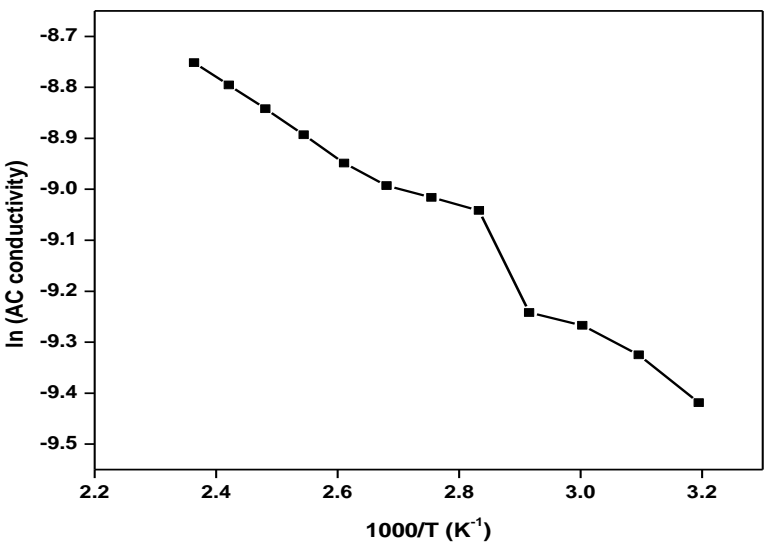

SS

Fig. 5: Plot $\ln \sigma_{\mathrm{ac}}$ versus 1000/T for DAHPT crystal at $1 \mathrm{kHz}$

\subsection{Impedance studies}

National Conference on Current Advancements in Physics $3^{\text {rd }} \& 4^{\text {th }}$ February 2017 
The complex impedance spectroscopy (CIS) [16] is a simple and nondestructive technique to study the electrical processes and conduction mechanism in the materials. This technique is based on analyzing the response of a system to an alternating field, and hence evaluation of impedance and related parameters as a function of frequency and temperature is studied [17, 18]. The real (resistive) and imaginary (reactive) components of impedance of the materials have been calculated using the following basic equation,

Complex impedance $Z^{*}=Z^{\prime}-j Z^{\prime \prime}=R_{s}-\left(j / \omega C_{s}\right)$

where $\omega$ is the angular frequency, $R_{s}$ and $C_{s}$ are resistance and capacitance in series respectively. In this work, the measurements on impedance of the grown Di-Ammonium Hydrogen Phospho Tartrate crystals were carried out using an impedance analyser (Model: IM 6 ZAHNER/GermanyElectrochemical Workstation) to find the impedance, bulk resistance, and DC conductivity of the samples.

Fig. 6 shows the variation of real part of impedance (Z') with frequency at different temperatures. The $Z$ ' values for all temperatures merge above $100 \mathrm{kHz}$. This may be due to the release of space charges. The curves also display single-relaxation process and indicate increase in ac conductivity with the increase in temperature and frequency. Fig. 7 shows the variation of $Z^{\prime \prime}$ with frequency at different temperatures. The high value of impedance at low frequency indicates low ion mobility. This also indicates the single-relaxation process in the system.

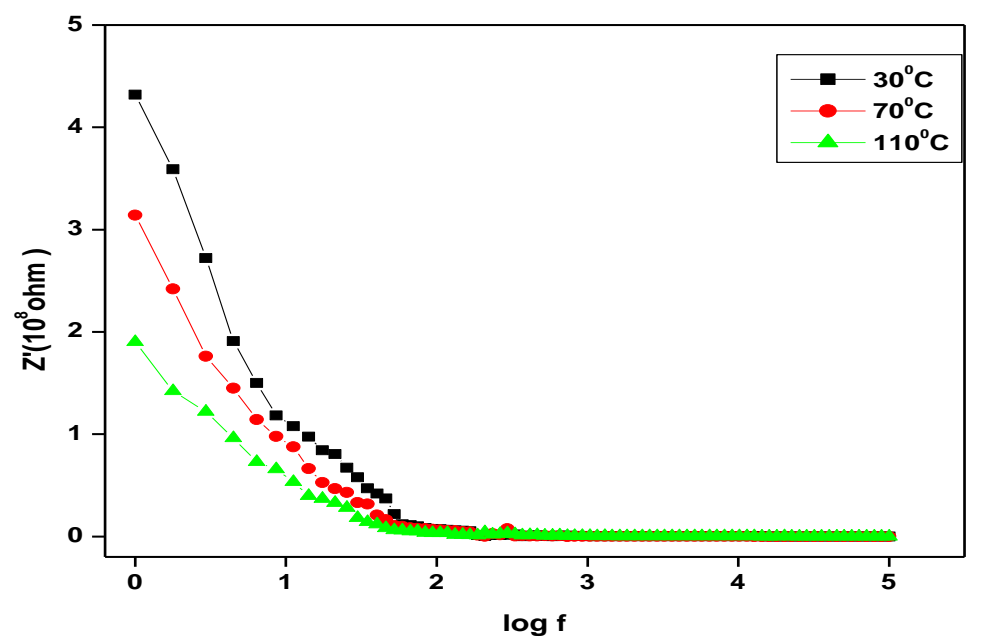

Fig. 6: Plot of real part of impedance versus frequency for DAHPT crystal

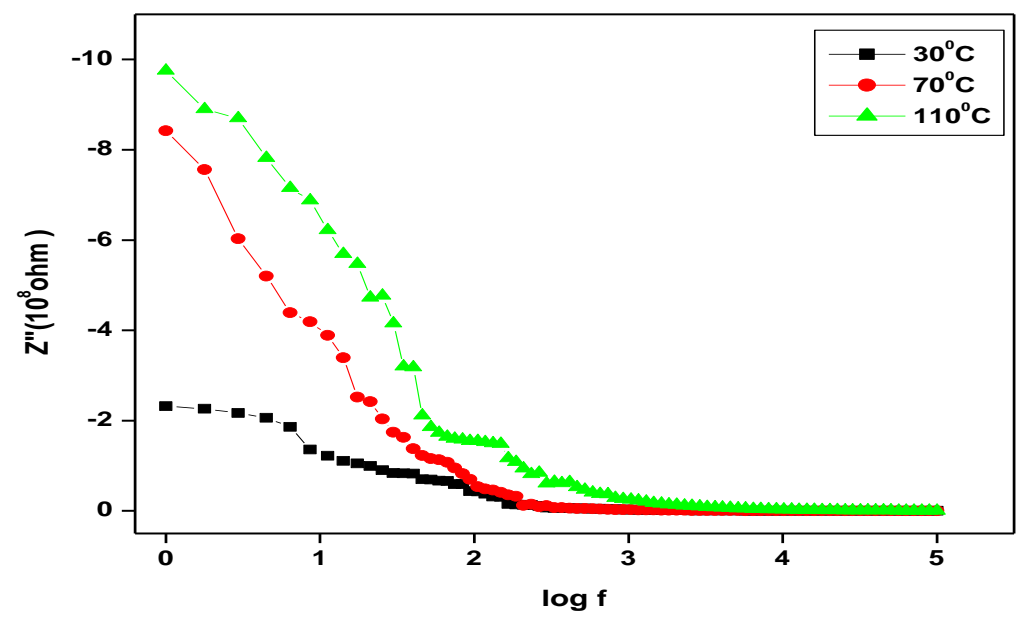

Fig. 7: Plot of imaginary part of impedance versus frequency for DAHPT crystal 


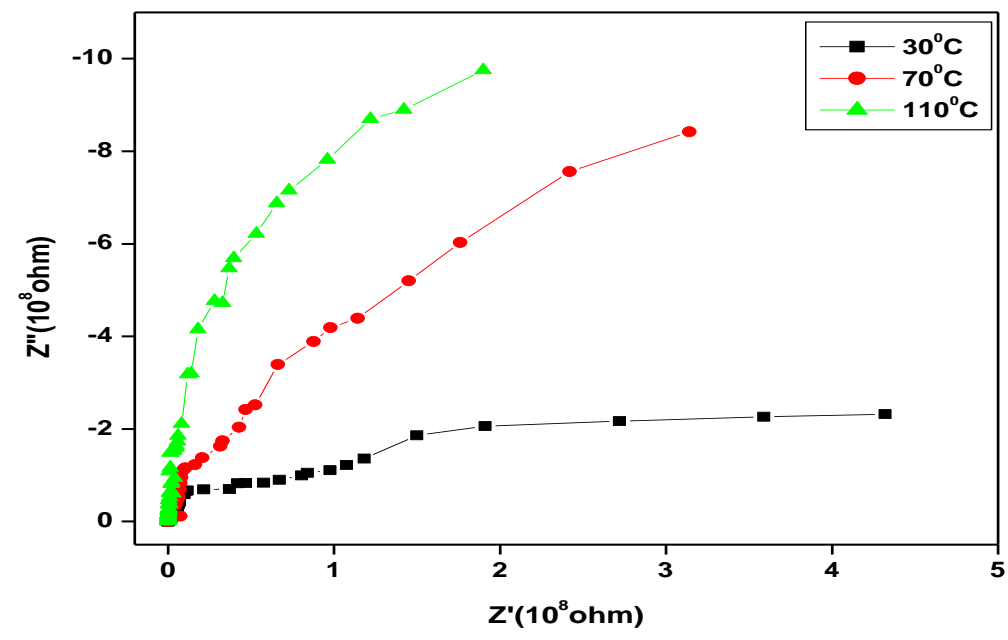

Fig. 8: Nyquist plot of DAHPT crystal

Fig. 8 shows a set of impedance data taken over a wide frequency range at several temperatures as a Nyquist diagram. The value of bulk resistance $\left(\mathrm{R}_{\mathrm{b}}\right)$ at different temperatures has been obtained from the intercept of semi circular arc on the real axis ( $\left.Z^{\prime}\right)$. From the Nyquist plot, it is clear that the value of $R_{b}$ decreases with increase of temperature. This shows the negative temperature co-efficient of resistivity behavior like that of semiconductor.Fig.9 shows the variation of $\sigma_{\mathrm{dc}}$ against temperature and Fig.10 shows the variation of conductivity against $10^{3} / \mathrm{T}$. The nature of variation is almost linear over a wide temperature region indicating the ohmic nature of contact and conductivity obeys the Arrhenius relationship $\sigma_{\mathrm{dc}}=\sigma_{\mathrm{o}} \exp \left(-\mathrm{E}_{\mathrm{a}} / \mathrm{KT}\right)$, where $E_{\mathrm{a}}$ is the activation energy of conduction and $\mathrm{T}$ is the absolute temperature. The nature of variation shows the negative temperature coefficient of resistance (NTCR) behaviour of DAHPT [19]. The low value of activation energy obtained could be attributed to the influence of electronic contribution to the conductivity.

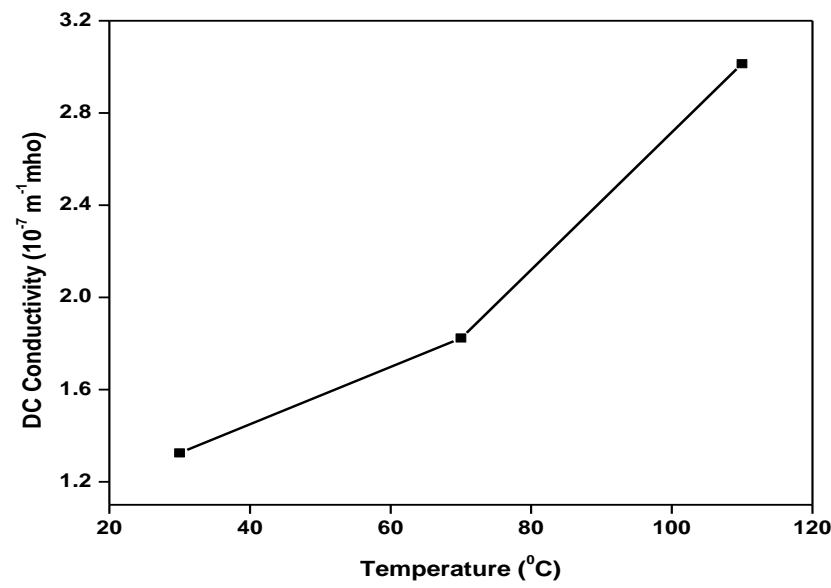

Fig.9: Variation of DC conductivity of DAHPT crystal as a function of temperature 


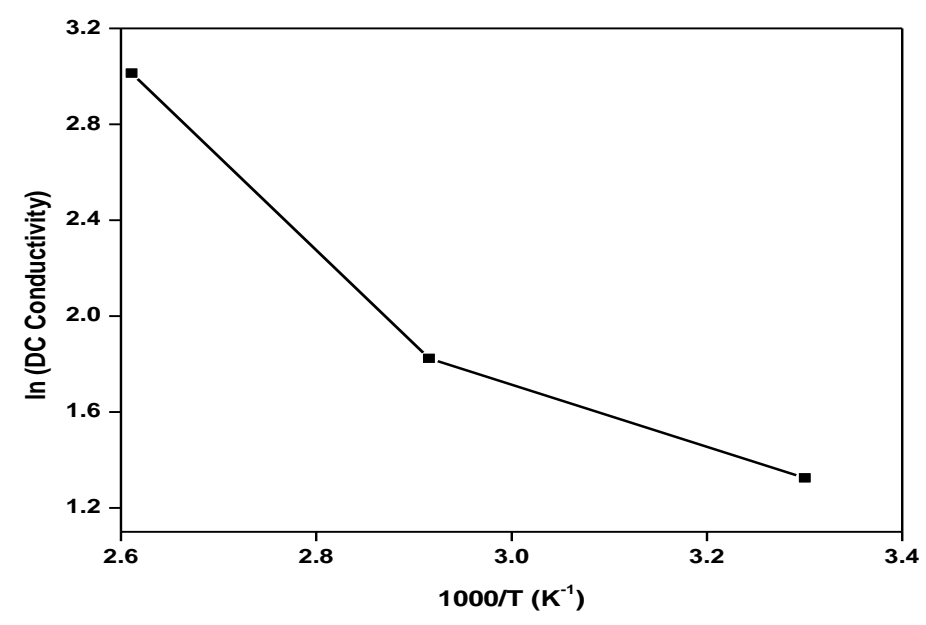

Fig.10: Variation of ln D.C conductivity of DAHPT crystal with inverse of temperature

\subsection{Z-scan method}

Z-scan technique $[20,21]$ based on the spatial distortion of a laser beam, passed through a nonlinear optical material, is widely used in material characterization because of their simplicity, high sensitivity. Fig.11 shows the Open Aperture (OA) transmittance spectrum of DAHPT. This spectrum shows a symmetric valley about the focus which indicates the presence of positive NLA in the sample. Maximum absorption occurs when the sample is at the focal point of the lens. The closed aperture Z-scan curve of DAHPT is shown in Fig.12. The valley followed by a peak normalized transmittance curve obtained from the closed aperture Z-scan data indicates that the sign of the refraction nonlinearity is positive i.e. self-focusing [22].

The measurable quantity $\Delta \mathrm{T}_{\mathrm{p}-\mathrm{v}}$ can be defined as the difference between the normalized peak and valley transmittances, $T_{p}-T_{v}$. The variation of this quantity as a function of $\left|\Delta \varphi_{\mathrm{o}}\right|$ is given by

$$
\Delta \mathrm{T}_{\mathrm{p}-\mathrm{v}}=0.406(1-\mathrm{S})^{0.25}\left|\Delta \varphi_{\mathrm{o}}\right|
$$

where $\mathrm{S}=1-\exp \left(-\mathrm{r}_{\mathrm{a}}{ }^{2} / \omega_{\mathrm{a}}{ }^{2}\right)$ is the aperture linear transmittance, $\Delta \varphi_{\mathrm{o}}$ is the on-axis phase shift. The on-axis phase shift is related to the third-order nonlinear refractive index by

$\Delta \varphi_{\mathrm{o}} \mid=\mathrm{kn}_{2} \mathrm{~L}_{\text {eff }} \mathrm{I}_{\mathrm{o}}$,
where $\mathrm{k}=\frac{2 \pi}{2}, \mathrm{~L}_{\mathrm{eff}}=\frac{\left[1-\exp \left[-\mathrm{xL} \mathrm{L}_{]}\right]\right.}{\mathrm{x}}$ is the effective thickness of the sample, $\alpha$ is the linear absorption coefficient, $\mathrm{L}$ the thickness of the sample, $\mathrm{I}_{\mathrm{o}}$ the on-axis irradiance at focus and $\mathrm{n}_{2}$ the third order nonlinear refractive index.

Generally the measurements of the normalized transmittance versus sample position, for the cases of closed and open aperture, allow determination of $\mathrm{n}_{2}$ the nonlinear refractive index and the saturation absorption coefficient $\beta$.

The nonlinear absorption coefficient $\beta$ can be estimated from the open aperture Z-scan data as [23]

$$
\beta=\frac{2 \sqrt{2 \Delta T}}{I_{0} L_{\text {eff }}}
$$

The experimental measurements of $\mathrm{n}_{2}$ and $\beta$ allow one to determine the real and imaginary parts of the third-order nonlinear optical susceptibility $\chi^{(3)}$ according to the following relations [24]

$$
\operatorname{Re} \chi^{(3)}(\mathrm{esu})=10^{-4} \frac{\mathrm{E}_{0} \mathrm{c}^{2} \mathrm{n}_{0}^{2}}{\mathrm{~m}} \mathrm{n}_{2} \mathrm{~cm}^{2} / \mathrm{W}
$$

where $\varepsilon_{0}$ is the vacuum permittivity, and $\mathrm{c}$ is the velocity of light.

The absolute value of $\chi^{(3)}$ is calculated from

$$
\operatorname{Im} \chi^{(3)}(\mathrm{esu})=10^{-2} \frac{\mathrm{E}_{0} \mathrm{C}^{2} \mathrm{n}^{2} \mathrm{Z}}{4 \mathrm{\pi}^{2}} \beta \mathrm{cm}^{2} / \mathrm{W}
$$

$$
\chi^{(3)}=\sqrt{\left(\operatorname{Re}(\gamma)^{\mathrm{a}}\right)^{2}+\left(\operatorname{Im}(\gamma)^{\mathrm{a}}\right)^{2}}
$$




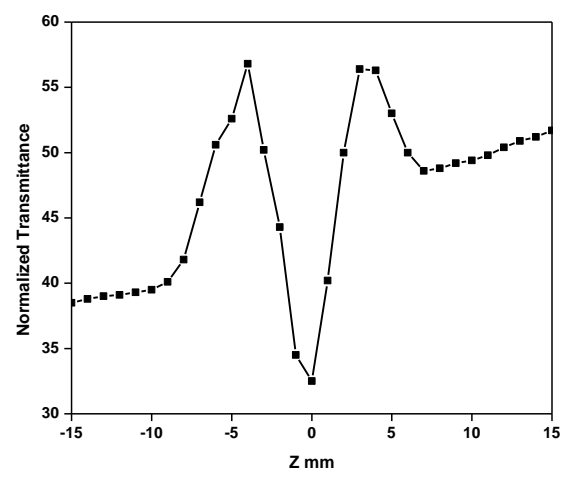

Fig. 11: Open aperture curve of DAHPT crystal

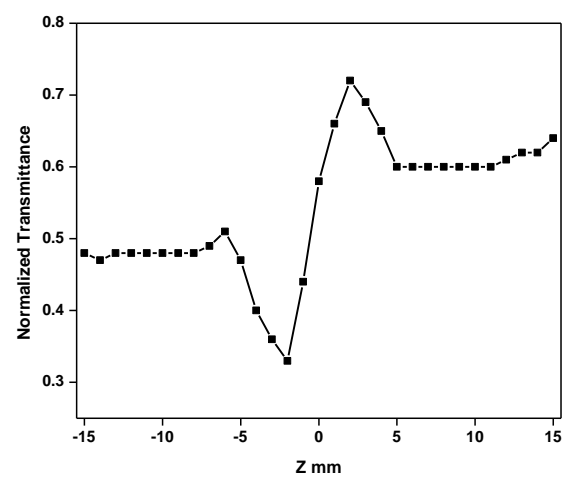

Fig. 12: Closed aperture curve of DAHPT crystal

The nonlinear parameters such as nonlinear refractive index $\mathrm{n}_{2}$, nonlinear absorption coefficient $\beta$, and nonlinear susceptibility $\chi$, has been evaluated and tabulated in Table 2 .

Table 2 Nonlinear optical parameters of DAHPT crystal

\begin{tabular}{|l|l|l|l|}
\hline Compound & $\mathrm{n}_{2} \times 10^{-12}\left(\mathrm{~m}^{2} / \mathrm{W}\right)$ & $\beta \times 10^{-4}(\mathrm{~m} / \mathrm{W})$ & $\chi^{(3)} \times 10^{-6}$ esu \\
\hline DAHPT & 2.27795 & 0.5331 & 2.2578 \\
\hline
\end{tabular}

\section{Conclusion}

DAHPT single crystals were grown by slow evaporation solution method at room temperature. Single crystal study shows that the crystal belongs to orthorhombic structure. Dielectric characterization shows that the DAHPT sample is polarized in an external electric field and dielectric loss indicates that the grown DAHPT crystals are of good quality and AC conductivity increases with temperature indicating the dielectric nature of the sample. The real and imaginary parts of the impedance are found to be decreasing with increase of frequency for DAHPT crystal. From the Nyquist plot, the DC conductivity of the DAHPT crystal was calculated. The third order parameters of the grown crystal were determined for the grown crystal.

\section{Acknowledgement}

The authors would like to thank the staff members of M.K.University (Madurai), S.T. Hindu College (Nagercoil), PSN Engineering College (Tirunelveli), VIT University (Vellore) for having helped us to carry out the research work. Also we thank the authorities of management of Aditanar College of Arts and Science, Tiruchendur, Govindammal Aditanar College for Women, Tiruchendur, and S.T Hindu College, Nagercoil for the encouragement given to us to carry out the research work.

\section{References}

[1]. D.S Chemla and J.Zyss (Eds) Nonlinear Optical properties of organic molecule and crystal, Vol 1\& 2,

[2]. Academic Press, New York.

[3]. R.W. Boyd, Nonlinear Optics, Academic Press, San Diego (1992).

[4]. D.Xu., M.Jang.,Z.Ton., Acta chem.sin.,41(1983)570.

[5]. Tapati Mallik.,Tanusree Kar.,Journal of crystal Growth,285(2005) 178.

National Conference on Current Advancements in Physics $3^{\text {rd }} \& 4^{\text {th }}$ February 2017

Department of Physics, St. John's College, Palayamkottai-627 002, Tamilnadu, India. DOI 10.9790/4861-17002033138 
[6]. S.J. Nandre, S.J. Shitole, R.R. Ahire, Study of Growth, EDAX, Optical properties and Surface Morphology of Zinc Tartrate Crystals, Journal of Nano- and Electronic Physics, 4 (2012) 04013-04016.

[7]. S. J. Nandre, S. J. Shitole, R. R. Ahire, Structure, surface morphology and thermal study of strontium tartrate crystals grown in silica gel by single diffusion method, Advances in Appl. Sci. Research, 4 (2013) 223-231.

[8]. R. Gandhimathi, C. Muthukrishnan, P. Selvarajan, Growth and Characterizations of Manganese Sulpho Tartrate (MST) - a semiorganic NLO crystal, Optik 126 (2015) 2925-2929.

[9]. M. Meena, C.K. Mahadevan, Growth and electrical characterization of L-arginine added KDP and ADP single crystalsCryst. Res. Technol., 43 (2008) 166-172.

[10]. S.M. Dharmaprakash, P. Mohan Rao, Dielectric properties of hydrated barium oxalate and barium cadmium oxalate crystals, J. Mater. Sci. Lett., 8 (1989) 1167-1168.

[11]. G. Babu Rao, P. Rajesh, P. Ramasamy, A study on the growth, optical, thermal, mechanical, dielectric and piezoelectric properties of dye doped KAP single crystals, Mater. Res. Bull., 60 (2014) 709-713.

[12]. S.S. Gupta, R.D. Pradhaban, A. Marcano, O.N. Melikechi, C.F. Desai, Laser damage studies in zinc (tris) thiourea sulfate: Nonlinear optical crystal, J. Appl. Phys., 91 (2002) 3125-3128.

[13]. U. Charoen - ln, P. Ramasamy, P. Manyum, Unidirectional growth of organic nonlinear optical L-arginine maleate dihydrate single crystal by Sankaranarayanan-Ramasamy (SR) method and its characterization, J. Cryst.Growth, 318 (2011) 745-750.

[14]. D. Sankar, V.R. Menon, P. Sagayaraj, J. Madhavan, Thermal, mechanical, electrical, linear and nonlinear optical properties of l-arginine dihydrofluride single crystal, Physica B, 405 (2010) 192-197.

[15]. Ginson P.Joseph, K.Rajarajan, M.Vimalan, S.Selvakumar, S.M.Ravikumar, J.Madhavan and P.Sagayaraj, Spectroscopic, thermal and mechanical behaviour of Allylthiourea cadmium chloride single crystals, Mater. Res. Bull., 42 (2007) 2040-2047.

[16]. S.Mukerji, T.Kar, Vicker's Microhardness Studies of L-arginine Hydrobromide Monohydrate Crystals (LAHBr), Cryst. Res.Technol.,34 (1999) 13.

[17]. J.R. Macdonald, Impedance Spectroscopy Emphasizing Solid Materials and Systems, Wiley, New York, (1987).

[18]. B.N. Parida, R. Das Piyush, R. Padhee, R.N.P. Choudhary, J. Phys. Chem. Solids, 73 (2012) 713.

[19]. S. Brahma, R.N.P. Choudhary, A.K. Thakur, AC impedance analysis of LaLiMo2O8 electroceramics, Physica B, 355 (2005) 188-201.

[20]. C.K. Suman, K. Prasad, R.N.P. Choudhary, Impedance analysis of Pb2Sb3LaTi5O18 ceramic, Mater. Chem. and Phys., 97 (2006) 425-430.

[21]. M. Sheik-Bahae, A.A. Said, E.W. VanStryland, High-sensitivity, single-beam n2 measurements, Opt. Lett., 14 (1989) 955-957.

[22]. M. Sheik-Bahae, A.A. Said, T.H. Wei, D.J. Hagan, E.W. VanStryland, Sensitive measurement of optical nonlinearities using a single beam', IEEE J. Quan.Elect., 26 (1990) 760-769.

[23]. E.G. Sauter, Nonlinear optics, John Wiley\& Sons Inc, Newyork (1996).

[24]. C. Gayathri, A. Ramalingam, Single-beam Z-scan measurement of the third-order optical nonlinearities of azo dyes, Spectrochim. Acta Part A, 68 (2007) 578-582.

[25]. R.Santhakumari, K. Ramamurthi, Structural, thermal and optical characterization of an organic NLO materialBenzaldehyde thiosemicarbazone monohydrate single crystals, Spectrochim. Acta Part A, 78 (2011) 653-659. 